Asian J. Med. Biol. Res. 2018, 4 (4), 400-405; doi: 10.3329/ajmbr.v4i4.40113

\author{
Asian Journal of \\ Medical and Biological Research \\ ISSN 2411-4472 (Print) 2412-5571 (Online) \\ www.ebupress.com/journal/ajmbr
}

\title{
Article \\ Knowledge, attitude and practice towards use of herbal aphrodisiac among unani \& ayurvedic health care seekers in Dhaka city
}

\author{
Mohammed Saiful Islam Chowdhury ${ }^{1}$, Md. Monir Ahammed ${ }^{2}$, Mohammad Abu Taher $^{2}$, Md. Anisur Rahman ${ }^{3}$ \\ and M.S.A Mansur Ahmed ${ }^{4}$ \\ ${ }^{1}$ Rawsan Jahan Estern Medical College, Dattapara, Lakshmipur, Bangladesh \\ ${ }^{2}$ Faculty of Unani and Ayurvedic Medicine, Hamdard University Bangladesh, Hamdard City of Science, \\ Education \& Culture, Gazaria, Munshiganj-1510, Bangladesh \\ ${ }^{3}$ Biopharma Laboratories, Dhaka, Bangladesh \\ ${ }^{4}$ Daffodil International University, Dhaka, Bangladesh
}

*Corresponding author: Mohammed Saiful Islam Chowdhury, Department of Unani Medicine Rawsan Jahan Estern Medical College, Dattapara, Lakshmipur, Bangladesh. Phone: +8801674791866; E-mail: msicbd77@gmail.com

Received: 07 December 2018/Accepted: 23 December 2018/ Published: 30 December 2018

\begin{abstract}
Geographically Bangladesh is the treasure-house of medicinal plants especially herbal aphrodisiac medicines. The World Health Organization (WHO) reported that $70 \%-80 \%$ of the global population relies on herbs for primary health care. Sexual health is a state of complete physical, mental and social well-being in all aspects related to the reproductive system. The study aimed as assessing the use of herbal aphrodisiac among Unani \& Ayurvedic health care seekers in Dhaka city, knowledge, attitude and practice. The study design was a descriptive cross-sectional study. This study was conducted at Unani and Ayurvedic Medical College Hospital among 220 patients at Mirpur-13, Dhaka using a semi-structured interviewed questionnaire. The study result depicted that $47.7 \%$ respondents were in $21-30$ years age group. The mean age was $31.22 \pm 8.265$ years and the range was from 17-50 years. It was found that the prevalence of Premature Ejaculation (PE) and Erectile Dysfunction (ED) was $26.4 \%$ and $21.8 \%$ respectively. Low level of knowledge was found about different aspects of Unani and Ayurvedic System of Medicine. It was revealed that most of the respondents (95\%) knew about the very effective aphrodisiac, their safety and cost issue. It was also revealed that most $(79.1 \%)$ of the respondents strongly opined about less side-effect of herbal aphrodisiac. The study findings suggest that there is a significant association between age and knowledge about Govt. teaching hospital and between education and knowledge about cost of aphrodisiac in herbal medicine.
\end{abstract}

Keywords: herbal aphrodisiac; premature ejaculation; erectile dysfunction; unani and ayurvedic medicine

\section{Introduction}

Since ancient times, herbs have played an important role in the treatment of different diseases in many regions of world, largely for their expectorant, aphrodisiac, diuretic, diaphoretic, antispasmodic, stomachic, and sedative properties. The World Health Organization (WHO) reported that $70 \%-80 \%$ of the global population relies on herbs for primary health care. In addition, because they are natural products, it is generally believed that herbs are essentially safe and free from side effects. Consequently, the consumption of nonprescription herbs has steadily increased over the past few decades (Dayyak et al., 2015). Diseases are the destroyers of health and life. They manifest themselves as a hindrance in leading a happy and healthy life. Day to day stress at work and home also adds to the hostile environment against good health. Among the men, this stress also exhibits a negative impact on their sexual health (Chaudhry et al., 2014). Sexual health is very important if people want to have responsible, safe, and satisfying sexual lives. The knowledge the adolescents acquire about sexual health 
during this period is an important indicator in the development of healthy sexuality. The attitudes, beliefs and myths/misconceptions these adolescents hold and the about sexuality may impair normal sexual activity leading to psychosexual health problems. Recent population-based surveys among men reveal a high prevalence psychosexual health concerns like premature ejaculation, Dhat syndrome, impotence, dissatisfaction, erectile dysfunction and nocturnal emissions. Premature ejaculation (PE) is one of the most common psychosexual disorders where myths and misconceptions of sexual health like semen loss concerns are high (Harti, 2014).

Sexual health is a state of complete physical, mental and social well-being in all aspects related to the reproductive system. Compromised sexual abilities may lead to infertility. Male sexual dysfunction (MSD) resulting in unsuccessful intercourse may adversely affect the personal and social life of the suffer couples and also contributes to infertility. MSD may be due to decreased libido, erectile dysfunction and disorders of ejaculation. A number of factors including psychological disturbances (performance anxiety, strained relationship, depression, stress, guilt and fear of sexual failure), deficiencies in sex hormones (testosterone deficiency), chronic diseases (diabetes, hypertension, atherosclerosis, venous leakage), neurological disorders (Parkinson's disease, Alzhemier's disease, spinal cord or nerve injury), side effects associated with chronic use of drugs (anti-hypertensives, central agents, psychiatric medications, antiulcer, antidepressants, anti-androgens), life style related complications (chronic alcohol abuse, cigarette smoking) and aging are known to contribute to MSD (Sharma et al., 2014).

An aphrodisiac is a substance that increases sexual desire. Many foods, drinks, and behaviors have had a reputation for making sex more attainable and/or pleasurable. The name comes from Aphrodite, the Greek goddess of sexuality and love, and substances are derived from plant, animal or mineral and since the time immemorial the have been the passion of man. Men and women alike have continued to use aphrodisiacs whether or not these drugs have any scientific basis of truly improving sexual satisfaction without regards to their composition. For centuries men and women have attempted to enhance their sexual experiences with a variety of chemicals. There is a rich history in all cultures of using substances derived from plants and animals, as well as synthetic materials, to change the sexual experience. Aphrodisiac can be classified by their mode of action into three types, those that can increase libido, potency or sexual pleasure (Bello, 2015).

Aphrodisiacs can be classified according to their effects when consumed or administered. Aphrodisiacs can have psychological effects, thereby increasing sexual desire and pleasure through hallucinogenic properties or other mood stimulating properties. Aphrodisiacs can also act physiologically, enhancing erection through hormonal changes, increased blood flow, and smooth muscle-relaxing properties. Sexual enhancer advertisements and other popular cultural depictions therefore participate in putting the spotlight on the performing penis as integral to masculinity. Sexual enhancers thus becomes a pill not only to repair, but also to enhance or improve, both erectile functioning and masculinity. Sex, does not occur merely between the individual partners directly involved, instead sex occurs within a broader social and cultural context, with implications for prestige, status, and reputation. In summary, aphrodisiacs have now become a means to enhancing a person's self-image (Sankar, 2001).

The study on knowledge, attitude and practice towards use of herbal aphrodisiac among Unani and Ayurvedic healthcare seekers will find out the knowledge, attitude and practice among patients towards herbal aphrodisiac. It will also find out the awareness and acceptance of the patients about the Unani and Ayurvedic Health Care Services. It is expected that the findings of the study will provide information that will lead toward a comprehensive strategy for the betterment of ailing people of Bangladesh at both govt. and NGO levels.

\section{Materials and Methods}

The study design was a descriptive cross-sectional study. This study was conducted at Unani and Ayurvedic Medical College Hospital at Mirpur-13, Dhaka. The study was conducted from January to April 2017. Sample population of this study was patients attending in Out Patient Department (OPD) of Unani and Ayurvedic Medical College Hospital, Mirpur, Dhaka. The age of patient attending at OPD were 17-50 with both sexes and who was willing to participate in the study were included in the study. Patients who are mentally sound too. Sample size of this dissertation proposal was calculated with $95 \%$ significance level. $\mathrm{P}$ is considered $50 \%$ since the data or similar finding of the population that were not available $[\mathrm{n}=(\mathrm{z} 2 \mathrm{p} * \mathrm{q} / \mathrm{d} 2) * \mathrm{DE}]$. A total of 220 patients were selected randomly and interviewed using PPS method. Structured questionnaire were developed for face to face interview. Data of this study were managed and analyzed through SPSS version 16 and Stata 8.0 version. Data management and analysis was included entry and entry verification, cleaning and processing of data, coding and code transfer, development of analysis plan, analysis program development \& program running and report generation. Ethical clearance was approved by the ethical review committee of the Daffodil International University, Dhaka. 


\section{Results}

\subsection{Age of the respondent}

Table- 1 shows that the respondents were divided in to 4 groups. It was also found that Mean \pm SD (years) was $31.22 \pm 8.265$ and the range was 17-50 years. Most of the respondents were in the age group of 21-30 years and their percentage was $47.729 \%$ of the respondents were in the age group of $31-40$ years, $13.6 \%$ in the age group 41 years $\&$ above. A little $9.5 \%$ respondent was in the age group of up to 20 years.

\subsection{Gender of the respondent}

It was found that $184(83.6 \%)$ respondents were 'male' and $36(16.4 \%)$ was 'female'.

\subsection{Religion of the respondent}

Study findings shows that most (92.7\%) of the respondents were 'Islam' by religion and $16(7.3 \%)$ was 'Hinduism' by religion, showing the lowest percentage.

\subsection{Education of the respondent}

According to educational qualification, 86 (39.1\%) respondents had 'graduate' level of education, showing the highest percentage. Followed by 73 (33.2\%), 23 (10.5\%), 20 (9.1\%) and $18(8.2 \%)$ was 'Higher secondary', 'Illiterate', 'Secondary' and 'primary' level of education respectively.

\subsection{Occupation of the respondent}

It was found that $81(36.8 \%)$ respondents were 'service' by occupation, showing the highest percentage. Followed by 72 (32.7\%) was 'Business', 35 (15.9\%) was 'Others', 24 (10.9\%) was 'House wife' and 8 (3.6\%) respondents were 'Day laborer' by occupation, showing the lowest percentage.

\subsection{Income of the respondent}

The study population was divided into 5 income level group. In terms of personal income, the study revealed that $61(30.8 \%)$ respondents were in 'Tk. 15001-25000' income level group, showing the highest percentage. Followed by 47 (23.7\%) was in 'Tk. 35001-45000' income level group, 46 (23.2\%) was in 'Tk. 25001-35000' income level group, $34(17.2 \%)$ was in up to 'Tk. 15000' income level group and $10(5.1 \%)$ respondents were in 'Tk. 45001 and above income level group, showing the lowest percentage. It was also found that Mean $\pm \mathrm{SD}$ (Tk.) was 27823.23 \pm 11714.630 and the range was Tk. 5000-50000.

\subsection{Disease related issues}

Table-2 shows that $26.4 \%$ respondents had 'Premature ejaculation' problem, showing the highest percentage. Followed by $21.8 \%$ Erectile dysfuction, $7.7 \%$ Low libido, 5.9\% Leucorrhea, $4.1 \%$ Loss of libido, 2.3\% Polyuria with burning, $1.4 \%$ Loss of sensation and $0.9 \%$ respondents had Short sexual duration problem showing the lowest percentage. It was found that majority of the respondents $(70.0 \%)$ had same disease before, showing the highest percentage and $30 \%$ did not have same disease before.

According to pattern of physician half of the respondents (50\%) received treatment from 'Homeopathy doctor', showing the highest percentage. Followed by $34.4 \%$ received treatment from 'Allopathic doctor', 9.7\% from 'Ayurvedic doctor', $4.5 \%$ from 'Unani doctor' and 1.3\% respondents received treatment from 'Pharmacy man', showing lowest percentage.

\subsection{Knowledge related issues}

Table-3 shows that most of the respondents $(89.5 \%)$ did not know about the degree level education for herbal medicine, showing the highest percentage and $23(10.5 \%)$ knew there is an arrangement of degree level education for herbal medicine. It was found that most of the respondents $(91.9 \%)$ did not know the name of the university showing the highest percentage and $8.1 \%$ knew it was Dhaka University. It showed that most of the respondents $(95 \%)$ knew about the very effective aphrodisiac in herbal medicine, showing the highest percentage and 5\% did not know about the very effective aphrodisiac in herbal medicine. According to the knowledge about safety of aphrodisiac in herbal medicine $100 \%$ said they are safe. It was found that knowledge about cost of aphrodisiac in herbal medicine $100 \%$ said they are costly. 
Table 1. Distribution of the respondents by Socio-demographic and socio-economic characteristics $(\mathbf{n}=\mathbf{2 2 0})$.

\begin{tabular}{|c|c|c|c|c|c|}
\hline \multirow{3}{*}{ Parameters } & & \multicolumn{4}{|c|}{ Age groups } \\
\hline & & \multirow{2}{*}{$\frac{\text { Up to } 20 \mathbf{y}}{21(9.5)}$} & \multirow{2}{*}{$\frac{\mathbf{2 1 - 3 0} \mathbf{y}}{105(47.7)}$} & \multirow{2}{*}{$\begin{array}{l}31-40 \\
64(29.1) \\
\end{array}$} & \multirow{2}{*}{$\begin{array}{l}\geq \mathbf{4 1} \mathbf{y} \\
30(13.6)\end{array}$} \\
\hline & & & & & \\
\hline \multirow{2}{*}{ Sex } & Male & Female & & & \\
\hline & $184(83.6 \%)$ & $36(16.4 \%)$ & & & \\
\hline \multirow{2}{*}{ Religion } & Muslim & Hindu & & & \\
\hline & $204(92.7 \%)$ & $16(7.3 \%)$ & & & \\
\hline \multirow{2}{*}{$\begin{array}{l}\text { Educational } \\
\text { qualification }\end{array}$} & Illiterate & Primary & Secondary & Higher secondary & Graduate \\
\hline & $23(10.5 \%)$ & $18(8.2 \%)$ & $20(9.1 \%)$ & $73(33.2 \%)$ & $86(39.1 \%)$ \\
\hline \multirow{2}{*}{ Occupation } & House wife & Service & Business & Day laborer & Others \\
\hline & $24(10.9 \%)$ & $81(36.8 \%)$ & $72(32.7 \%)$ & $8(3.6 \%)$ & $35(15.9 \%)$ \\
\hline \multirow{2}{*}{$\begin{array}{l}\text { Monthly fam. } \\
\text { income }\end{array}$} & Up to Tk. 15000 & $\begin{array}{l}\text { Tk. } 15001- \\
25000\end{array}$ & $\begin{array}{l}\text { Tk. 25001- } \\
35000\end{array}$ & Tk. 35001-45000 & Tk. 45001 and \\
\hline & $34(17.2)$ & $61(30.8)$ & $46(23.2)$ & $47(23.7)$ & $10(5.1)$ \\
\hline
\end{tabular}

Table 2. Distribution of the respondents by disease pattern and care seeking behavior for herbal aphrodisiac drugs.

\begin{tabular}{lll}
\hline Variables & Frequency $(\mathbf{n}=\mathbf{2 2 0})$ & Percentage (\%) \\
\hline Disease pattern distribution & & \\
Erectile dysfunction & 48 & 21.8 \\
Loss of libido & 9 & 4.1 \\
Loss of sensation & 3 & 1.4 \\
Low libido & 17 & 7.8 \\
Polyuria with burning & 5 & 2.3 \\
Female frigidity & 13 & 5.9 \\
Premature ejaculation & 58 & 26.4 \\
Short sexual duration & 2 & .9 \\
Having same disease before & & \\
Yes & 154 & 70.0 \\
No & 66 & 30.0 \\
Treatment received for same disease (n=154) & & \\
Ayurvedic doctor & 15 & 9.7 \\
Unani doctor & 7 & 4.5 \\
Allopathic doctor & 53 & 34.4 \\
Homeopathy doctor & 77 & 50.0 \\
Pharmacy man & 2 & 1.3 \\
\hline
\end{tabular}

Table 3. Distribution of the respondents by knowledge about degree level education, university, herbal medicine department and company name.

\begin{tabular}{|c|c|c|}
\hline Variables & Frequency $(\mathbf{n = 2 2 0})$ & Percentage (\%) \\
\hline \multicolumn{3}{|c|}{ Knowledge about degree level education for herbal medicine } \\
\hline Yes & 23 & 10.5 \\
\hline No & 197 & 89.5 \\
\hline \multicolumn{3}{|c|}{ Knowledge about university name } \\
\hline Yes & 18 (University of Dhaka) & 8.1 \\
\hline No & 202 & 91.9 \\
\hline \multicolumn{3}{|c|}{$\begin{array}{l}\text { Knowledge about the very effective aphrodisiac in } \\
\text { herbal medicine }\end{array}$} \\
\hline Yes & 209 & 95.0 \\
\hline No & 11 & 5.0 \\
\hline \multicolumn{3}{|c|}{$\begin{array}{l}\text { Knowledge about safety of aphrodisiac in herbal } \\
\text { medicine }\end{array}$} \\
\hline It is safe & 220 & 100.0 \\
\hline \multicolumn{3}{|c|}{$\begin{array}{l}\text { Knowledge about cost of aphrodisiac in herbal } \\
\text { medicine }\end{array}$} \\
\hline It is costly & 220 & 100.0 \\
\hline
\end{tabular}




\section{Discussion}

Regarding the age of the respondents, present study found that the maximum of them (47.7\%) were between 21 30 years old. On the other hand $29.1 \%$ was between $31-40$ years and $13.6 \%$ was 41 years and above. It seems that $9.5 \%$ respondents of present study belong to age limit up to 20 years. (Table 1). Bello and Jibrin (2015) and Kalra et al. (2015) found that the maximum of the respondents' age limit was 21-30 years and 18-30 years respectively which is consistent with the present study. It was also found that the Mean $\pm \mathrm{SD}$ (years) was $31.22 \pm 8.265$ (Table 1). Akinloye and Yinusa (2015) found that the Mean \pm SD (years) was $32 \pm 2.4$ which is also consistent with the present study.

It was found that $83.6 \%$ respondents were 'male' and $16.4 \%$ was 'female' (Table 1). Mitha et al. (2013) found that out of 256 respondents, $92(35.9 \%)$ were male while $164(64.1 \%)$ were female. This differences indicates that the users of Complementary and Alternative Medicine (CAM)/Unani and Ayurvedic health care seeks' male and female ratio may vary depending on country, urban, rural background and educational level as well.

According to religion the present found that most (92.7\%) of the respondents were 'Islam' by religion and 16 $(7.3 \%)$ was 'Hinduism' (Table 1). It indicates about the real national scenario Hindu vs Muslim ratio of the country. On the other hand regarding educational background it was found that only $10.5 \%$ respondent was illiterate and rest of the respondent was $86(39.1 \%), 73(33.2 \%), 20(9.1 \%)$ and $18(8.2 \%)$ was 'Graduate' 'Higher secondary', 'Secondary' and 'primary' level of education respectively (Table 1). It indicates real phenomena that illiteracy is always low in urban area of the country.

It was revealed that among the respondents maximum of them $82(37.3 \%)$ had 'Tk. 35001-45000' monthly family income. On the other hand 56 (25.5\%) had 'Tk. 25001-35000', 47 (21.4\%) had 'Tk. 15001-25000', 20 (9.1\%) had 'Tk. 45001 and above' and 15 (6.8\%) respondents had up to 'Tk. 15000 monthly family income. It was also revealed that Mean \pm SD (Tk.) was $33750.00 \pm 11582.787$ and the range was Tk. 15000-80000. The economic situation of the respondents indicates the present socio-economic condition of the country.

Table 2 shows that $26.4 \%$ respondents had 'Premature ejaculation' problem, showing the highest percentage. Followed by $21.8 \%$ Erectile dysfuction, $7.8 \%$ Low libido, 5.9\% Female frigidity, $4.1 \%$ Loss of libido, 2.3\% Polyuria with burning, $1.4 \%$ Loss of sensation and $0.9 \%$ respondents Short sexual duration problem showing the lowest percentage. It was found that majority of the respondents $70.0 \%$ had same disease before, showing the highest percentage and 30\% did not have same disease before. According to pattern of physician half of the respondents $50 \%$ received treatment from 'Homeopathy doctor', showing the highest percentage. Followed by $34.4 \%$ received treatment from 'Allopathic doctor', 9.7\% from 'Ayurvedic doctor', $4.5 \%$ from 'Unani doctor' and $1.3 \%$ respondents received treatment from 'Pharmacy man', showing lowest percentage. Kalra et al., (2013) found that Premature ejaculation was the most common sexual dysfunction seen in the respondents and Suleiman et al., (2016) found that the most common men's health complication reported by pharmacist was erectile dysfunction $(\mathrm{n}=12,22.6 \%)$ which are consistent with the present study.

It was found that $70.0 \%$ respondents had same disease before and $50 \%$ received treatment from 'Homeopathy doctor'. On the other hand 34.4\% received treatment from 'Allopathic doctor', 9.7\% from 'Ayurvedic doctor', $4.5 \%$ from 'Unani doctor' and 1.3\% respondents received treatment from 'Pharmacy man' (Table 3). It indicates that patients tried to get treatment from Homeopathic doctor first due to low cost and then to Allopathic doctor due availability of doctors and medicines. Usually patients go to the Unani and Ayurvedic doctors as a third options as well as last options. Most of the respondents perceived that pharmacists are not currently authorized to dispense such remedies, did not receive any additional training related to such preparations and have limited access to information regarding herbal medicine. (Gelayee et al., 2017)

It was revealed that $89.5 \%$ respondent did not know about the degree level education for herbal medicine and $10.5 \%$ knew there is an arrangement of degree level education for herbal medicine. It was also found that most of the respondents $(91.3 \%$ ) did not know the name of the university that provides degree level education in Bangladesh. and only 10.5\% knew it was Dhaka University (Table-3). It indicates that as a new modality of medical care of government people may be unknown about education level and university name for Unani and Ayurvedic graduate level education.

\section{Conclusions}

- The present study found that the Mean age of the study population was $31.22 \pm 8.265$.

- Knowledge about efficacy of herbal aphrodisiac was found well and better among respondents. Most of the respondents strongly agreed that the side-effects of herbal aphrodisiac is less.

- Source of knowledge regarding herbal aphrodisiac was mainly from doctors and health workers.

- Significant association was found between age and use of herbal aphrodisiac. 


\section{Recommendations}

From this study the investigator picked up the knowledge, attitude and practice towards use of herbal aphrodisiac and then discussed those issues in light of national context and other study findings. This study suggests the following recommendations.

- Proper treatment and counseling program should be launched for sexual disorders specially 'Premature Ejaculation' and Erectile Dysfunction' adult unmarried men.

- Loss of libido issue should be given a special importance for due treatment.

- Sufficient in-depth study should be organized to provide a real insight into the sexual problems to allow a meaningful development.

\section{Acknowledgements}

I would like to express my heartiest gratitude to Dr. Md. Shah jahan, Head of the Department of Public Health, Daffodil International University (DIU), Prof. Dr. M.S.A Mansur Ahmed for guiding and supervising me to carry out this research, Dr. A.B.M Alauddin Chowdhury and Dr. Salamat Khondoker on the way to decide the study subject and Dr. Md. Anisur Rahman, Manager, Production Department, Bio Natures Ltd. Dhaka.

\section{Conflict of interest}

None to declare.

\section{References}

Akinloye OO and R Yinusa, 2011. Assessment of complementary and alternative medicine (CAM) usage to enhance male sexual performance in Ogbomoso metropolis. J. Public Health Epidemiol., 3: 271-274.

Atindanbila S, AS Mawusi, A Attiogbe, E Abasimi and P Amooba, 2014. Bio-Psychological factors associated with the use of sexual enhancers among Ghanaian men. International Journal of Research GRANTHAALAYAH, 2: 20-37.

Bello UL and I Jibrin, 2015. Use of Herbal Medicines and Aphrodisiac Substances among Women in Kano State, Nigeria. IOSR Journal of Nursing and Health Science (IOSR-JNHS); 4(4): 41-50. e-ISSN: 2320 1959.p- ISSN: 2320-1940.

Chaudhry P, N Lamba, BL Mehra, CP Kashyap, 2014. Clinical evaluation of Vanga Bhasma as Vrishya. Int. J. Res. Ayurveda Pharm., 5: 406-411.

Dayyak MA, EO Nath, G Ozhan, 2015. Toxic potentials of ten herbs commonly used in for aphrodisiac effect in Turkey. TURK. J. MED. SCI., 45: 496-506.

Sankar D, 2001. The Role of Traditional and Alternative Health Systems In Providing Health Care Options: Evidence from Kerala. Delhi: Institute of Economic Growth. https://www.researchgate.net/search.

Gelayee DA, GB Mekonnen, SA Atnafe, MK Birarra and AB Asrie, 2017. Herbal Medicines: Personal Use, Knowledge, Attitude, Dispensing Practice, and the Barriers among Community Pharmacists in Gondar, Northwest Ethiopia. Hindawi Evidence-Based Complementary and Alternative Medicine; Volume 2017, Article ID 6480142, 6 pages.

Harti SS, 2014. Survey on Knowledge of reproductive and sexual health in the community and clinical evaluation of Veeryasthambha Vati in premature ejaculation. A Thesis for the award of the Degree of Doctor of Philosophy, Kle Deemed University, India.

Kalra G, R Kamnath, A Subramanyam and H Shah, 2015. Psychosocial profile of male patients presenting with sexual dysfunction in a psychiatric outpatient department in Mumbai, India. Indian J. Psychiatry, 57: 51-58.

Mithaa S, V Nagarajanb, MB Babar, MJA Siddiquic, SQ Jamshedc, 2013. Reasons of using complementary and alternative medicines (CAM) among elderly Malaysians of Kuala Lumpur and Selangor states: An exploratory study. J. Young Pharm., 5: 50-53.

Sharma P, P Bhardwaj, T Arif, I Khan, R Singh, 2014. Pharmacology, phytochemistry and safety of aphrodisiac medicinal plants: a review. Research and Reviews: Journal of Pharmacology and Toxicological Studies, 2: 118.

Suleiman AK, TM Khan, PM Emeka, S Ahmad and SM Mansoor, 2016. The public purchase of aphrodisiac products without prescriptions in the Alahsa region of KSA. J. Taibah Univ. Med. Sci., 11: 413-417. 